\title{
Analysis of Seepage through Earth Dams with Internal Core
}

\author{
Mohamed N. Salem \\ Prof. of Irrigation and Drainage Structures, \\ Water and Water Structures Engineering Dept., Zagazig University, \\ Zagazig, Egypt.
}

\author{
Hazem M. Eldeeb \\ Lecturer, Water and Water Structures Engineering Dept., \\ Zagazig University, Zagazig, Egypt.
}

\author{
Salma A. Nofal \\ Demonstrator, Higher Institute of Engineering and \\ Technology, Zagazig, Egypt.
}

\begin{abstract}
Seepage flow through earth embankments is the primary cause that leads to failure due to eroding, scouring, and piping. Flow of water through soil can lead to movement of the soil grains. Continued movement causes erosion. Many factors can affect the movement of the soil grains including hydraulic gradient, soil plasticity, particle size, capillary tension, and others. In this research, seepage passing through the body of earth dam with/without internal core has been studied experimentally and numerically. Different models have been studied using GEOSTUDIO (2012) program in term of SEEP/W and SLOPE/W. SEEP/W was used to compute seepage, while SLOPE/W was used for the analysis of slope stability. Numerical results have been verified using experimental data from seepage and permeability model. The effect of core permeability, core width, core base thickness, and core penetration on seepage, pressure head, exit gradient, upstream and downstream slope stabilities have been studied. It's concluded that by Increasing of side slopes $(\mathrm{H}: \mathrm{V})$, a noticeable drop of seepage line is observed with increasing of downstream slope stability, by decreasing core permeability, increasing core thickness, base core thickness, and core penetration, the quantity of seepage and exit gradient decreased upstream slope stability decreased and downstream slope stability increased.
\end{abstract}

Keywords - Seepage; earth dam; core; finite element method; slope stability.

\section{INTRODUCTION}

Earthen dam is a structure composed of soil particle attached to each other and compacted in layers by mechanical means. Earth dams are usually trapezoidal in shape with a broad base. It was designed as a non-overflow section with a separate spillway. In this type of dams, the shear strength of soil ensures its stability. The three main types of earth dams are homogeneous, zoned and diaphragm earth dams [1].

Zoned dams are constructed with a central impervious core flanked by more pervious material known as shells. These pervious zones or shells support and protect the impervious core; the upstream pervious zone affords stability against rapid drawdown; and the downstream pervious zone acts as a drain to control seepage and lower the phreatic surface. The maximum width of the impervious zone is controlled by stability, seepage criteria, and by the availability of materials [2].
Erosion in earth structures due to water flow occurs when the erosion resistant forces are less than the seepage forces that tend to produce it. The resistant forces depend on the cohesion, the interlocking effect, the weight of the soil particles and the kind of protection they have downstream. Since the seepage through an earth structure is not uniform, the erosion phenomenon increases where there exists a concentration of seepage [3, 4].

\section{REVIEW OF PREVIOUS WORK}

There are several means to analyze seepage problems (analytical, experimental, and numerical), most of which used Darcy's law and Laplace equations [5].

Awal et al., (2009) [6] studied sudden failure of landslide dam in the experimental flume for steady discharge in the upstream reservoir. Sachpazis (2014) [7] studied the seepage inside the body of a homogeneous earth dam by means of drainage and seepage tank. Djehiche et al., (2014) [8] built a small-scale model of homogeneous earth dam with a vertical drain on a pervious foundation to determine the best position of a vertical drain in a homogeneous earth dam according to the maximum head of water. Shaaban et al., (2014) [9] studied two-dimensional unsteady state of unconfined seepage flow problems through earth dams using (Z_SOIL) numerical model taking required data from permeability and seepage experimental model of sand soil. Kanchana and Prasanna (2015) [10] analyzed the usage of different materials of earth dam with central impervious vertical core to study the behavior of phreatic line by varying effective length of horizontal drainage filter. Vazquez and Alejandro (2015) [11] built a model of zoned earth dam to identify the failure mechanisms of embankment dams by verifying the reliability of risk analysis after the breaching of the dam. Luofeng and Duan (2012) [12] studied the permeability and seepage stability of dams by the simulation of new structure of accumulating tubular geotextile sand-bags and casting sand-bags at the coastal reservoir storing fresh water Malekpour et al., (2012) [13] studied the effect horizontal drain size on the stability of an embankment dam in steady 
and transient seepage conditions. Xu et al., (2003) [14] developed a numerical scheme to calculate the optimal solution in an ideal earth dam cross section utilizing two different types of soil material. Tayfur et al., (2005) [15] developed FEM and artificial neural network (ANN) models to predict seepage through the body of Jeziorsko earthfill dam. Chen and Zhang (2006) [16] developed finite element method (FEM) and partial difference equation (PDE) using SVFLUX and FLEXPDE program respectively to simulate the movement of the water and the distribution of pore water pressure through Gouhou rock fill dam in two- and threedimensional analyses. Fu and Sheng (2009) [17] proposed a numerical model to simulate the unsteady seepage flow through dam using finite element method (FEM). Giglou and Zeraatparvar (2012) [18] analyzed seepage flow numerically with a two-dimensional finite element method through homogeneous earth dam. Li and Liu (2010) [19] established steady and transient models by using finite element software SEEP/W. They concluded that the small infiltration coefficient of the dam shell make the core bears the most head loss due to its little permeability, which may lead to excess hydrostatic pressure exerted on the core and adversely affect the stability of the dam. Ismaeel and Noori (2011) [20] analyzed Duhok zoned earth dam using finite element method (FEM) by SEEP2D computer program to study the effect of an isotropy of core material on seepage, and analyzed the stability using STABIL program. Shakir (2011) [21] studied the effect of an impervious core in reducing the quantity of seepage through earth dam. Two cases of core were studied: vertical core and core inclined towards upstream side. Hasani and Karimi (2013) [22] applied finite element method (FEM) using SEEP/W and SLOPE/W software to find out the seepage loss through Ilam fill dam by providing horizontal and vertical toe drains and internal core and to evaluated the stability of this dam under the following condition of dam, steady state, the sudden draw down, with three different methods: Bishop, Janbu, Ordinary method of Slices, and Morgenstem. Fakhari and Ghanbari (2013) [23] presented a new formula for calculating the quantity of seepage passing through embankment dams with vertical and oblique core. Karampoor and Riazi (2015) [24] calculated the seepage rate using SEEP/W and SPSS software of non-homogenous earth dam with clay core. Jamel (2016) [25] presented an approximate method of analysis involving the use of finite element technique (FEM) using computer program SEEP/W to study the behavior of seepage through a homogeneous earth dam without filter on impervious base. An empirical Equation (1) was developed to predict quantity of seepage under different conditions and the results were compared with artificial network (ANN), Depuit and Casagrande solution.

$$
Q=\frac{0.117 \times K \times F_{D} \times(\tan \theta)^{0.039} \times(\tan \alpha)^{0.681} \times\left(\frac{H}{F_{D}}\right)^{2.072}}{\left(\frac{F_{B}}{F_{D}}\right)^{0.194} \times\left(\frac{b}{F_{D}}\right)^{0.068}}
$$

Khassaf and Madhloom (2017) [26] studied the effect of use impervious core on seepage through Khassa Chai earth dam at different conditions such as core thickness and permeability using finite element method (FEM). Arshad and Javed (2017) [27] used the finite element method (FEM) to solve a two-dimensional unsteady flow through a homogeneous earth fill dam to study seepage and slope stability analysis using Geo-studio software (SEEP/W and SLOPE/W respectively) under a different condition. Kachare and Jagtap (2017) [28] analyzed seepage through Gangapur earth dam using Geo-Studio software depending on finite element method (FEM) to estimate seepage loss, exit gradient, uplift pressures, phreatic surface, and the amount of seepage to design a suitable dewatering system.

Souliyavong et al., (2012) [29] studied the effect of slope inclination, soil properties, and hydraulic conductivity on the stability of dam subjected to reservoir drawdown using general limit equilibrium method. Abdulkareem et al., (2014) [30] studied the safety of two existing zoned earthen dams in Kurdistan region, Iraq namely Duhok and Bawashawar dams.

In the present work, numerical and experimental and analyses have been performed to study the seepage flow through earth embankment and how to use the internal core to reduce it. The numerical analysis was verified using experimental model. The effect of core permeability, total core thickness, base core thickness and core penetration has been studied numerically to compute the behavior of seepage, exit gradient, pressure head using SEEP/W computer program; to analyze the stability of earthen dam using SLOPE/W program. SLOPE/W is formulation based on the general limit equilibrium method to find the critical factor of safety that resist the potential sliding.

\section{METHODOLOGY}

\section{A. Experimental study}

The physical model of an earth dam was constructed in a seepage and permeability model to investigate the behavior of seepage through the earth dam. It was equipped with 27 piezometers to measure the pore water pressure in steady state experiments. Two permeable perforated membranes were rigid fixed in the model before and after the soil to prevent it from getting through, as shown in Fig. 1. Fig. 2 shows the alignment of seepage and permeability model in the Hydraulics and Fluid Mechanics Laboratory, Faculty of Engineering, Zagazig University, Zagazig.

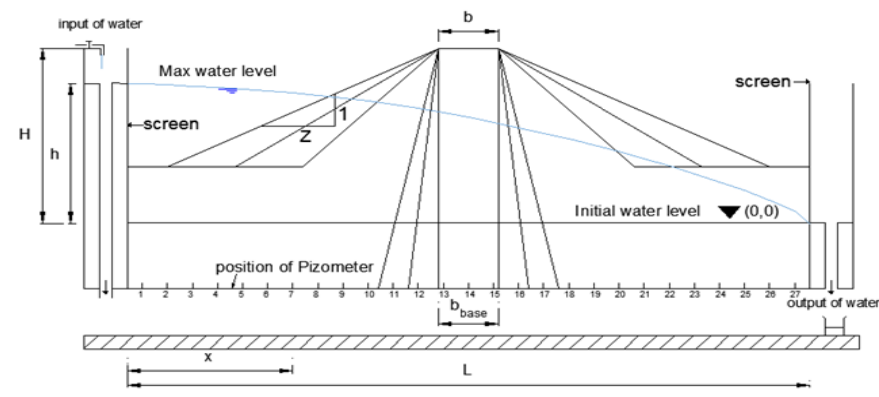

Fig. 1. Schematic view of the dam boundary 


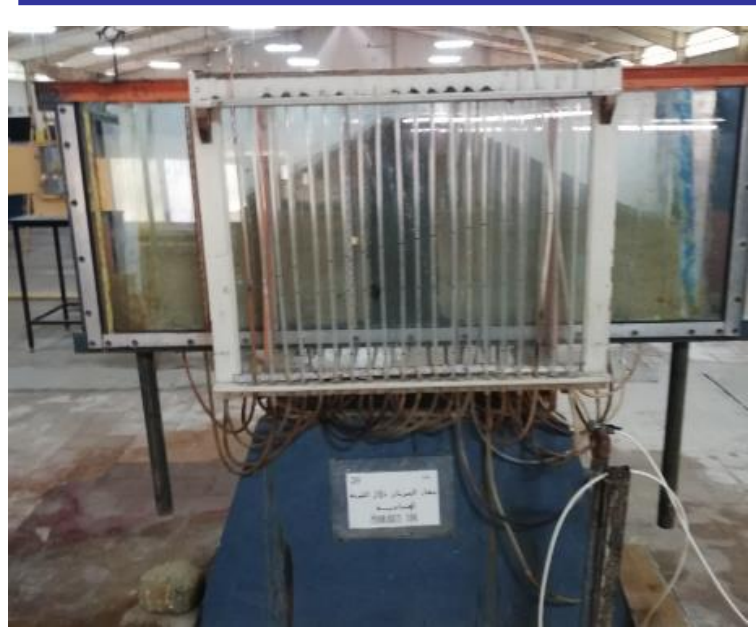

Fig. 2. Alignment of seepage and permeability model

\section{1) Homogeneous earth dam}

Three cases of sand model were studied varying upstream and downstream side slope $(\mathrm{H}: \mathrm{V})$ equal to $(1: 1,1.5: 1$, and 2:1) using seepage and permeability model as shown Fig.4 (case a, b, and c respectively). The value of upstream and downstream side slope were the same for three models. Table 1 shows the parameters used in the model such as; length, crest width, water height as a ratio of dam height. The grain size distribution curve for the soil type is shown in Fig. 3.

TABLE I.The Parameters used in the model

\begin{tabular}{|l|l|}
\hline \multicolumn{1}{|c|}{ parameters } & \multicolumn{1}{|c|}{ Value } \\
& \\
\hline Relative crest width $(\mathrm{b} / \mathrm{H})$ & 0.3 \\
\hline Relative dam base length $(\mathrm{L} / \mathrm{H})$ & 3.4 \\
\hline Relative water depth $(\mathrm{h} / \mathrm{H})$ & 0.8 \\
\hline Hydraulic conductivity $\left(\right.$ core/outer soil) $\mathrm{k}_{\text {core }} / \mathrm{k}$ & 0.0001 \\
\hline
\end{tabular}

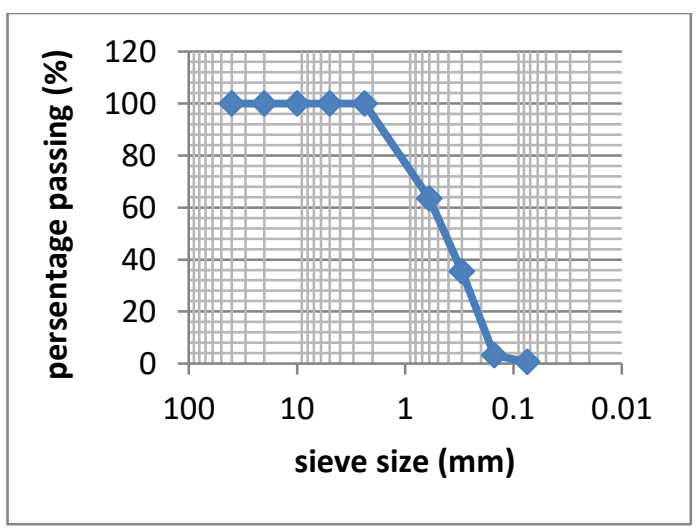

Fig. 3. Grain size distribution curve of sand soil.

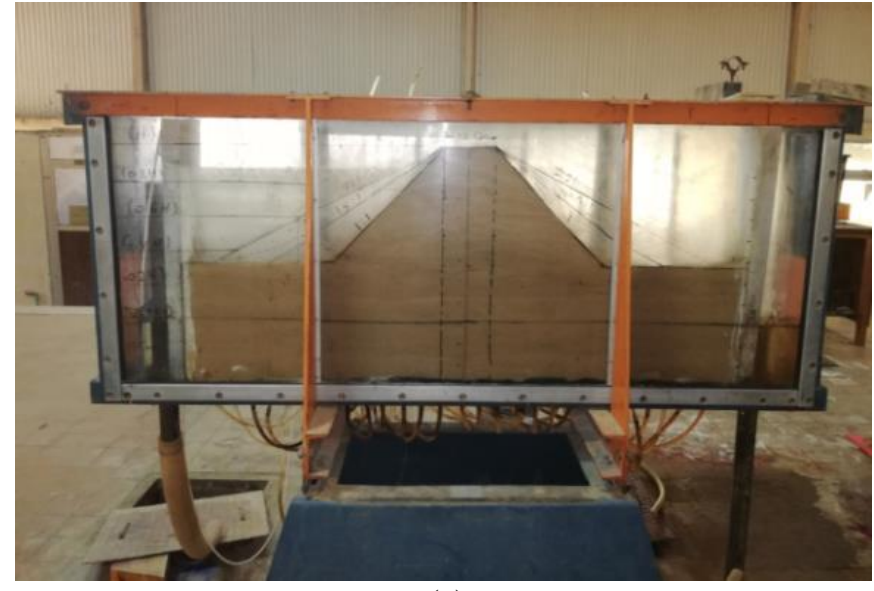

(a)

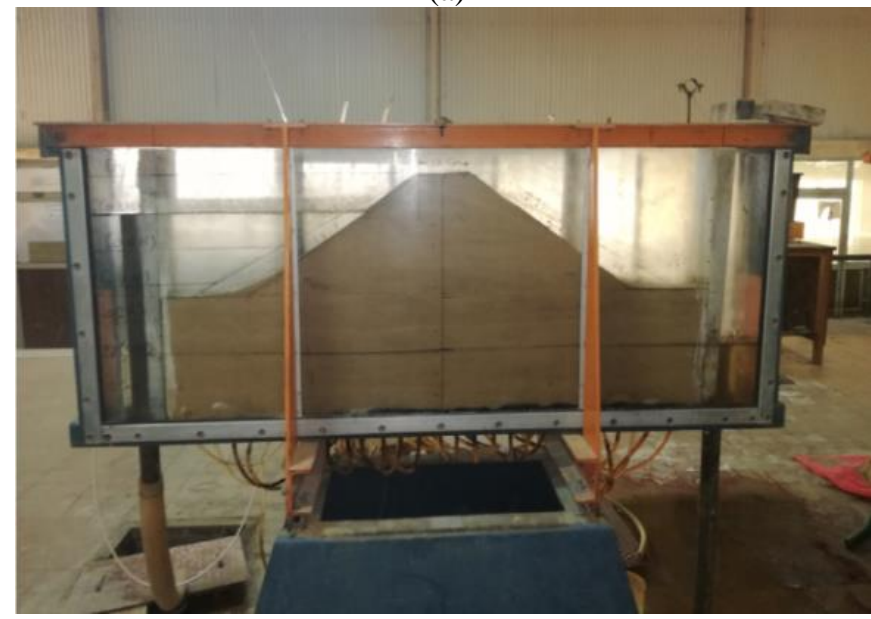

(b)

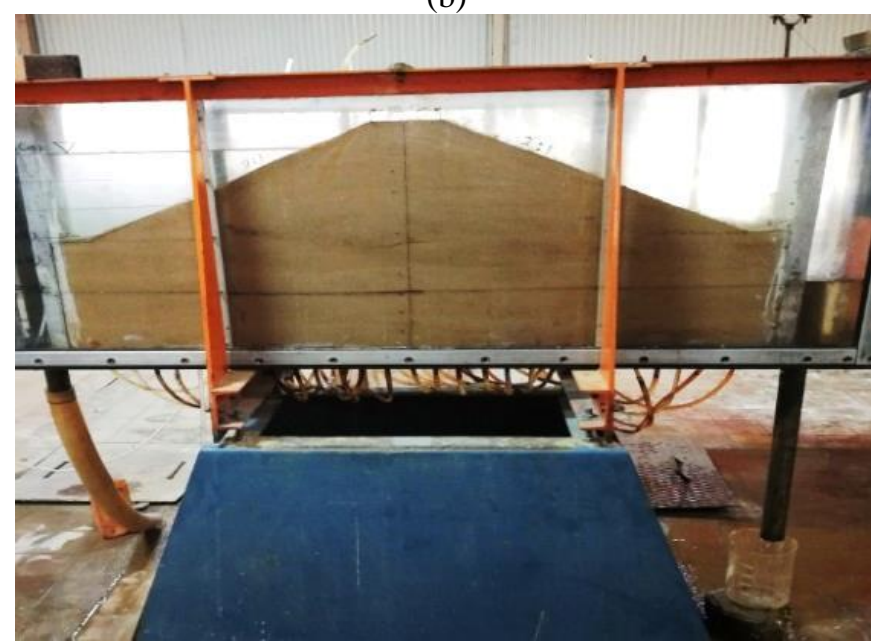

(c)

Fig.4. The experimental schematic view of the dam at different cases (a) slope $1: 1$; (b) slope $1.5: 1$; (c) slope $2: 1$

\section{2) Zoned earth dam}

To study the effect of clay core on seepage, three shape of clay core $(\mathrm{k}$ core $/ \mathrm{k}$ sand $=0.0001)$ at different $\mathrm{b}_{\text {base }} / \mathrm{b}=1,2$, and 3 shown in Fig. 5 (case 1, 2, and 3 respectively) were studied. All parameters for this dam were fixed (water depth, side slope, and hydraulic conductivity). 


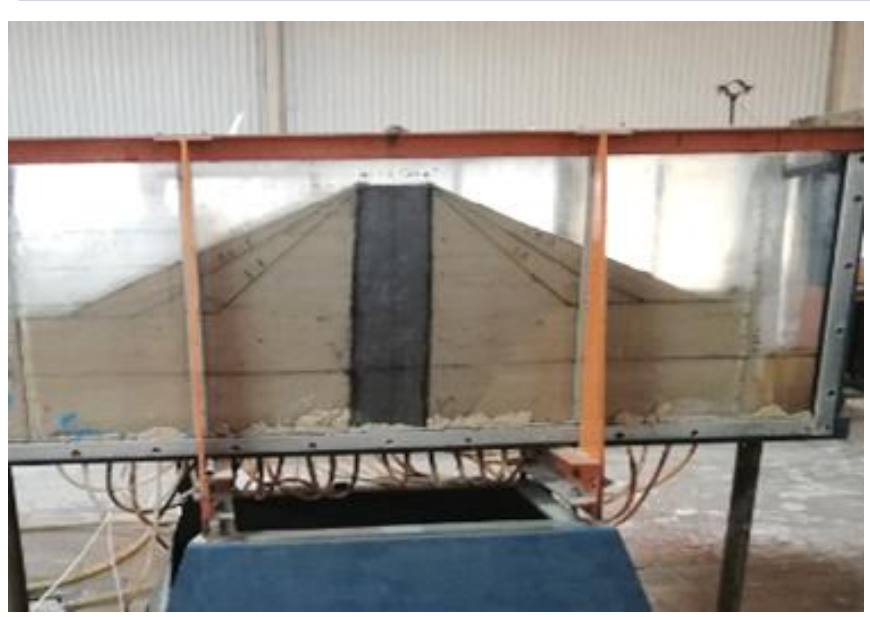

(a)

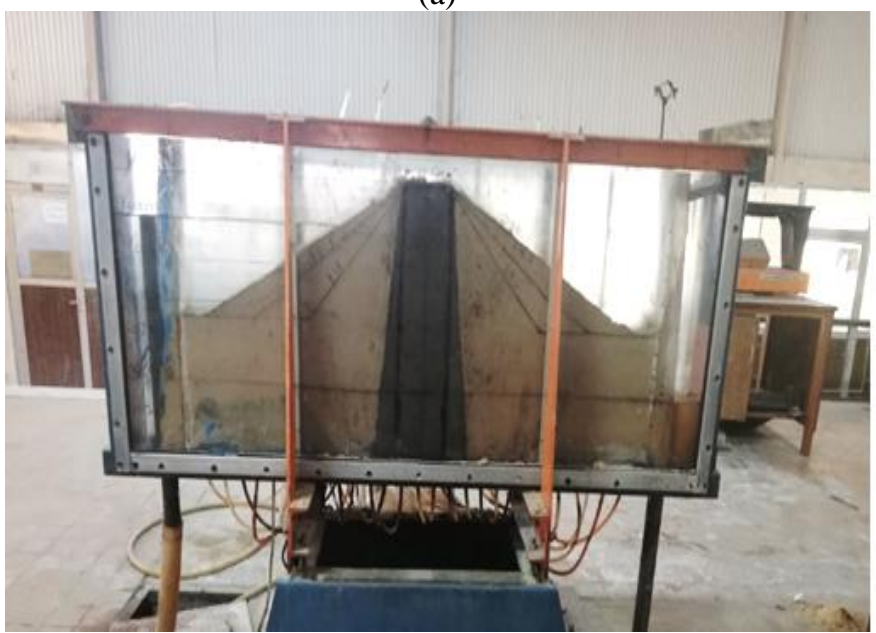

(b)

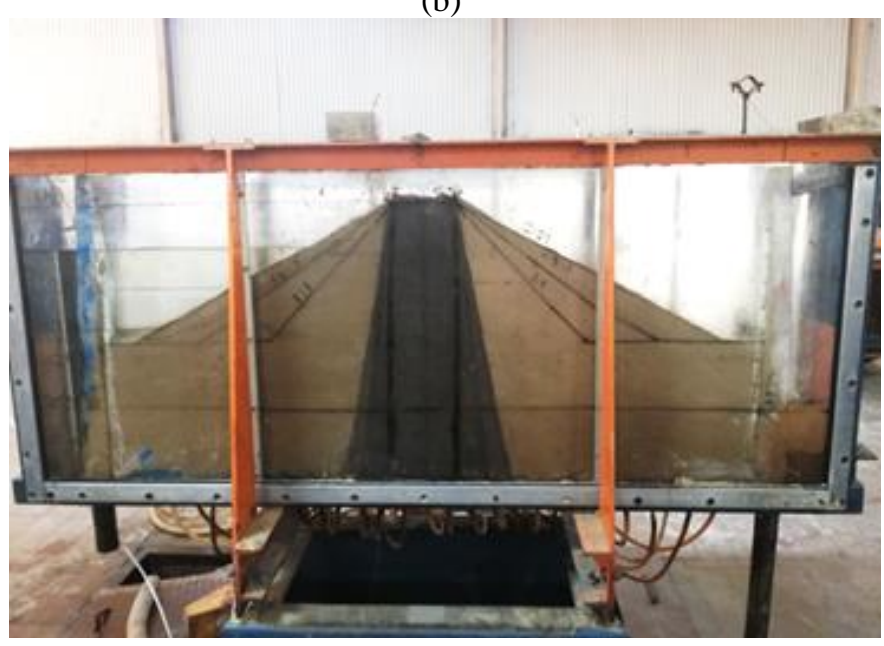

(c)

Fig. 5. The experimental schematic view of the dam at different cases (a) $b_{\text {base }} / b=1 ;$ (b) $b_{\text {base }} / b=2 ;$ (c) $b_{\text {base }} / b=3$

\section{B. Computer model}

Seepage analyses often performed within groups of geotechnical engineering using finite element numerical methods. In this research numerical computer program SEEP/W (part of GEOSTUDIO software package) used to analyze the fluid flow and the distribution of pore water pressure within porous media in saturated and unsaturated flow state. The saturated-only flow case is a confined flow such as seepage flow beneath a structure. The saturated and unsaturated flow is an unconfined flow problem, such as a flow through an earth dam. The finite element mesh pattern used in the model is Quads and triangle as shown in Fig. 6. The hydraulic conductivity function in SEEP/W estimated once Ksat value has been specified. Fig. 7 shows the hydraulic conductivity of soils used in the model.

The capability of the soil to store water under changes in metric pressure is reflected by volumetric water content (VWC). Degree of saturation of soil is equal to the VWC over the porosity of soil. In a saturated soil, VWC is equal the porosity of the soil. Fig. 8 shows typical values of VWC for sand, and clay soil

Fig. 9 shows the numerical schematic view of the dam at different cases of upstream and downstream side slope (a) slope $1: 1$; (b) slope $1.5: 1$; (c) slope $2: 1$

Fig. 10 shows the numerical schematic view of the dam at different cases of ( $b_{\text {base }} / b$ ) (a) $b_{\text {base }} / b=1$; (b) $b_{\text {base }} / b=2$; (c) bbase $/ \mathrm{b}=3$

The general governing differential equation for twodimensional seepage can be expressed as:

$$
\frac{\partial}{\partial \mathrm{x}}\left(\mathrm{k}_{\mathrm{x}} \frac{\partial \mathrm{H}}{\partial \mathrm{x}}\right)+\frac{\partial}{\partial \mathrm{y}}\left(\mathrm{k}_{\mathrm{y}} \frac{\partial \mathrm{H}}{\partial \mathrm{y}}\right)+\mathrm{Q}=\frac{\partial \theta}{\partial \mathrm{t}}
$$

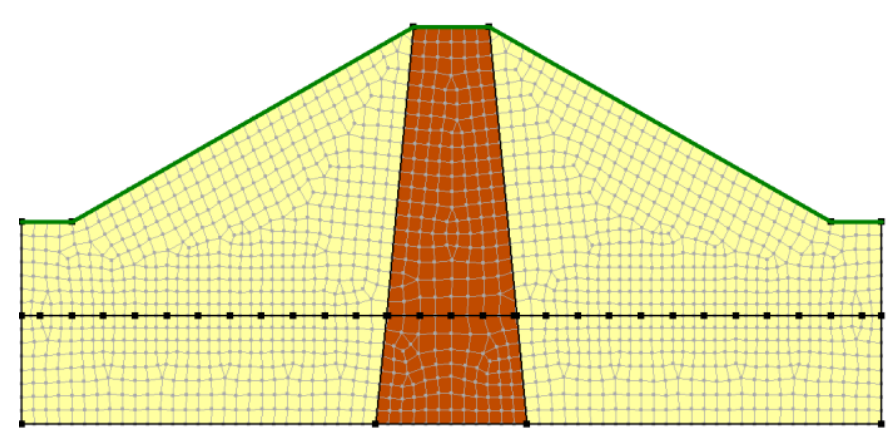

Fig. 6. Structured finite element mesh.

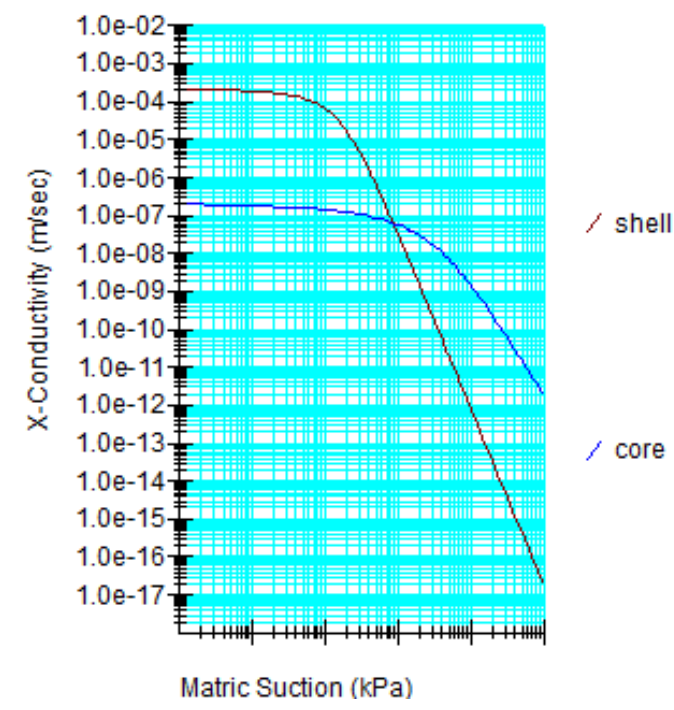

Fig. 7.the hydraulic conductivity of soils used in the model. 


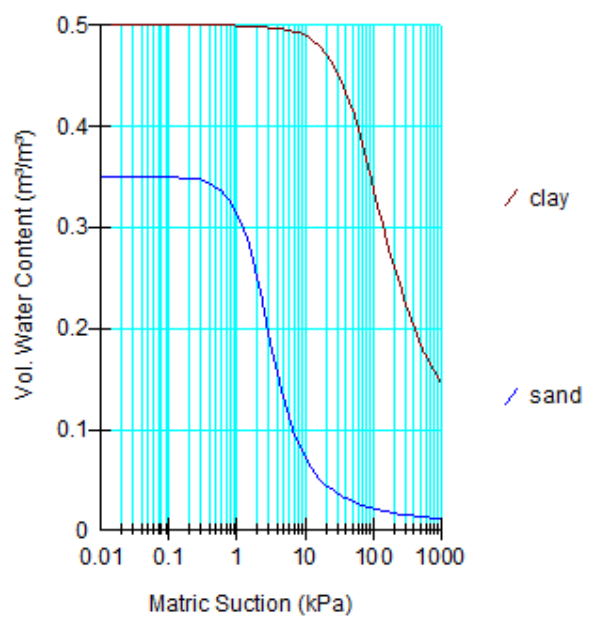

Fig. 8. Typical values of VWC for sand, and clay soil.

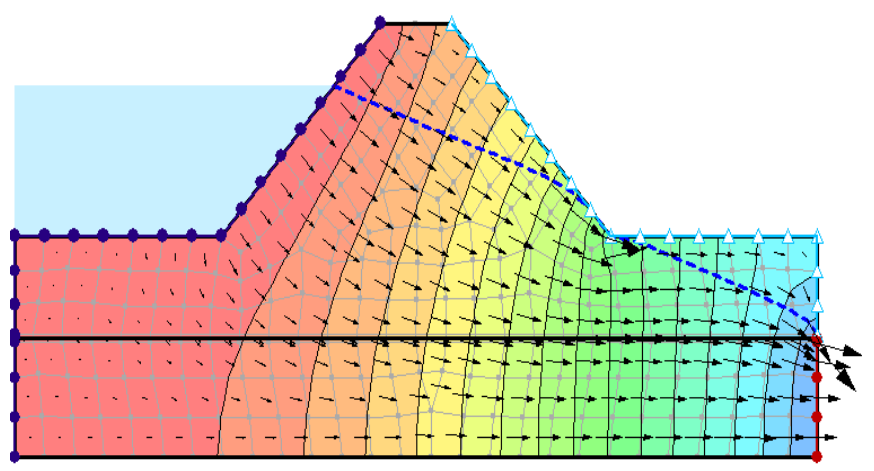

(a)

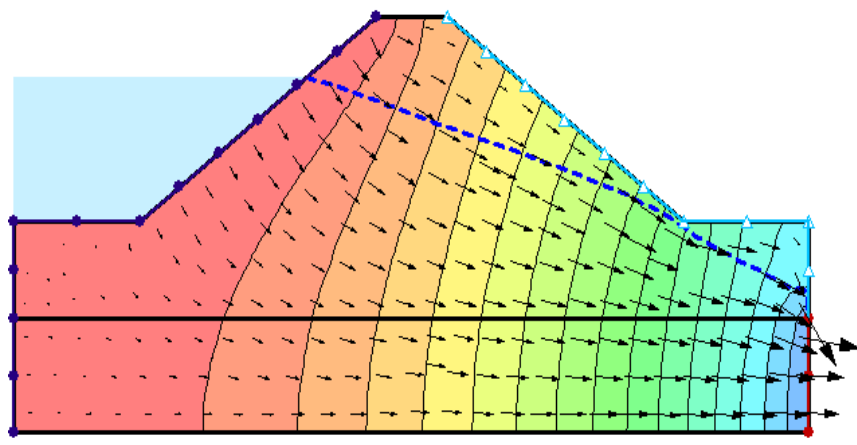

(b)

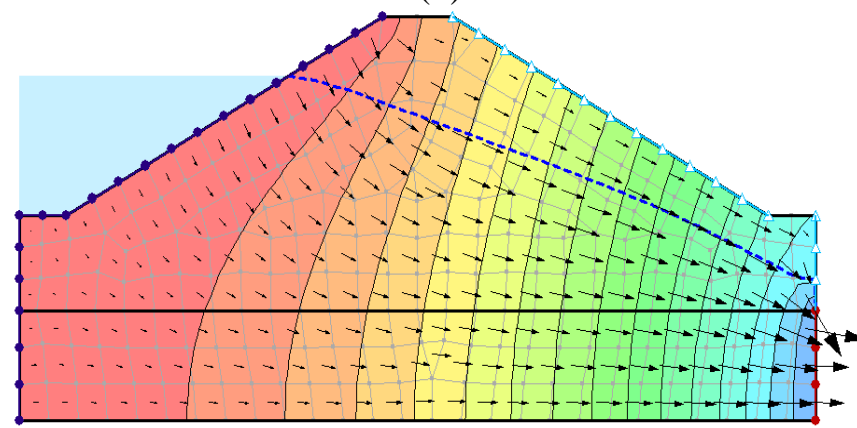

(c)

Fig. 9. The numerical schematic view of the dam at different cases of upstream and downstream side slope (a) slope 1:1; (b) slope 1.5:1; (c) slope $2: 1$.

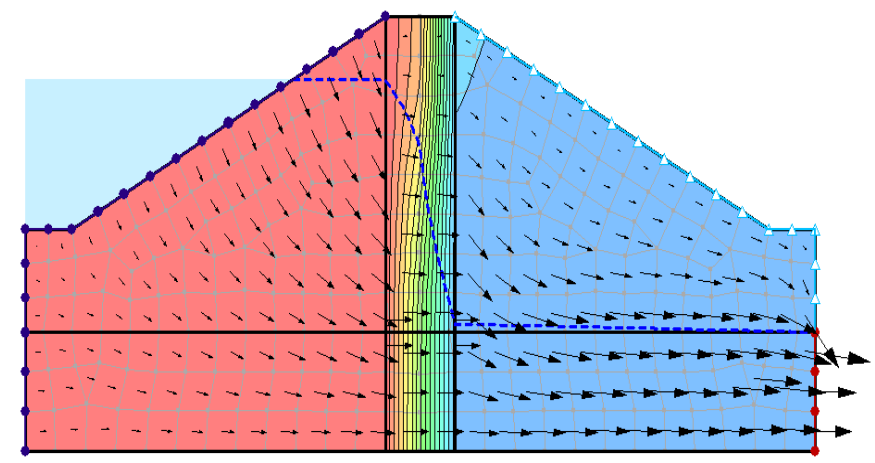

(a)

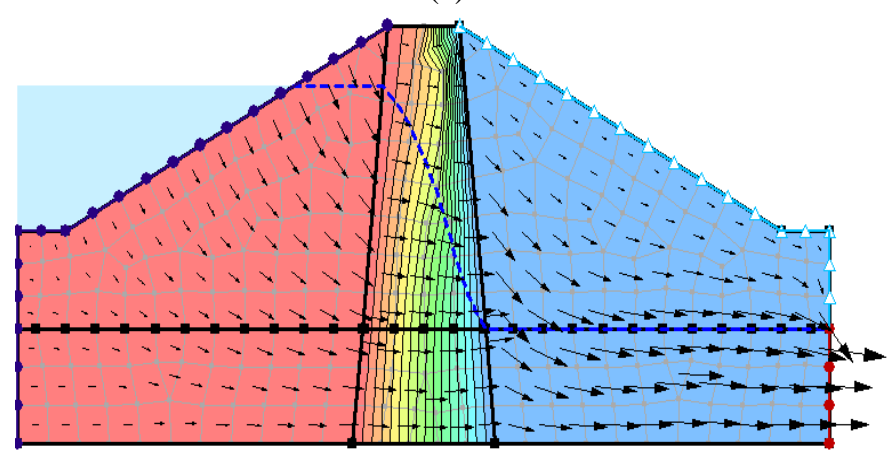

(b)

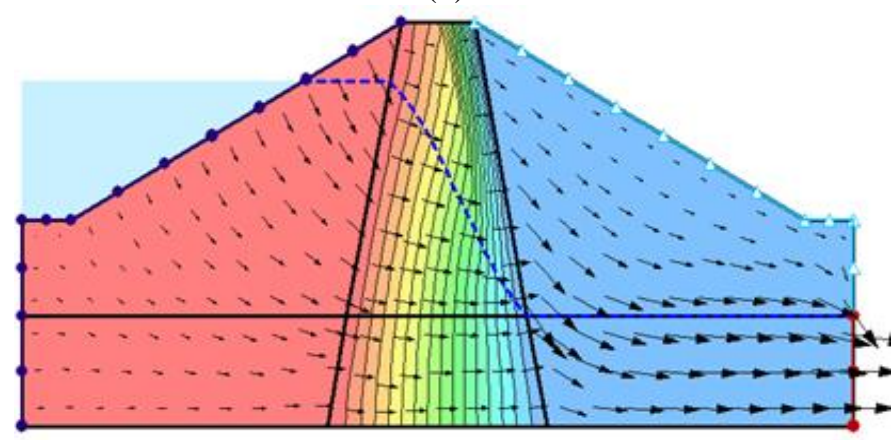

(c)

Fig. 10. The numerical schematic view of the dam at different cases of (b base/b) (a) bbase $/ \mathrm{b}=1$; (b) bbase/b=2; (c) bbase $/ \mathrm{b}=3$.

\section{Comparison between experimental and numerical work}

The experimental model results (using seepage and permeability model) and finite element model data using Geostudio software in term of SEEP/W were verified. The fundamental aspects of the finite element Modelling are the defining of the geometry, dividing the model into appropriate regions, defining material properties, and specification of the appropriate boundary conditions.

Fig. 11 shows comparison of seepage surface between numerical and experimental solution at different upstream and downstream side slope.

Fig. 12 shows Comparison of seepage surface between numerical and experimental solution at different $b_{\text {base }} / b$ at upstream and downstream side slope 2:1. 


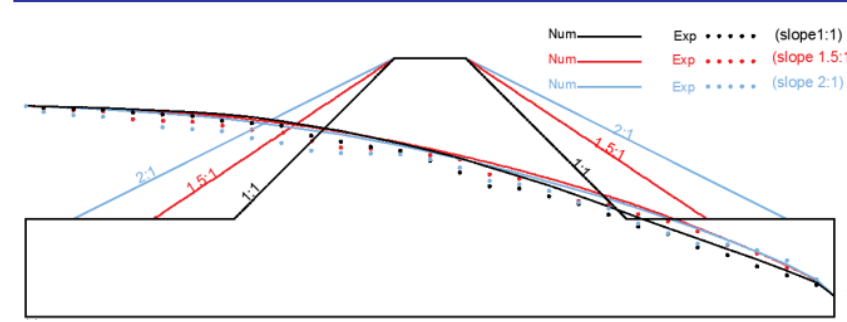

Fig. 11. Comparison of seepage surface between numerical and experimental solution at different upstream and downstream side slope (Z: 1) (dam without

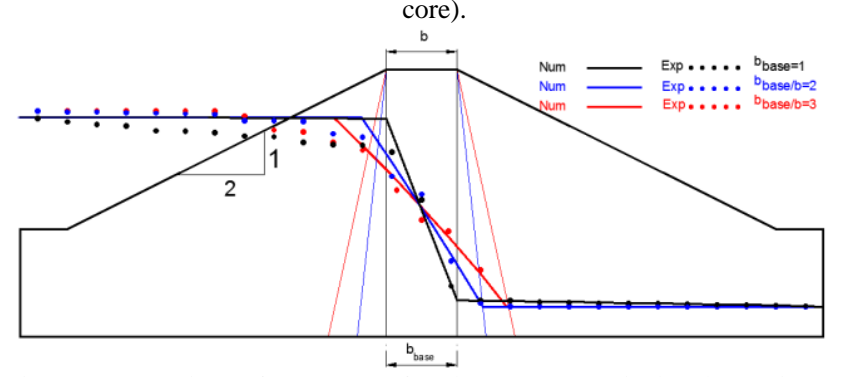

Fig. 12. Comparison of seepage surface between numerical and experimental studies at different $b$ base/b at upstream and downstream side slope 2:1(dam with core).

\section{NUMERICAL STUDY}

\section{A. SEEP/W analysis}

The fundamental aspects of finite element Modelling are discretization, defining material properties and boundary conditions. Creating the finite element model includes selecting an appropriate geometry, dividing the model into appropriate regions, and creating the discretized mesh.

Fig. 13 shows the coordinates of the main points required to define the geometry and dimensions of the dam cross section.

The most important soil property used in seepage analysis is the hydraulic conductivity (including an isotropy). In soils, the ability of water to transport saturated and unsaturated conditions is reflected by hydraulic conductivity function. The hydraulic conductivities of the materials used in the model are shown in Table 2

In steady state analysis, water pressure and water flow rate that reached a steady condition are independent of time. There are two choices of boundary conditions: a constant pressure (or head) or a constant flux rate. Fig. 14 shows boundary condition of steady-state condition used in model. Fig. 15 shows Places where data are gathered.

Table II. Parameters used in the model

\begin{tabular}{|l|l|}
\multicolumn{1}{|c|}{ Pable II. Parameters used in the model } \\
\begin{tabular}{|l|l|}
\hline \multicolumn{1}{|c|}{ Parameters } & \multicolumn{1}{c|}{ Value } \\
\hline Crest width (b) & $18 \mathrm{~m}$ \\
\hline Dam length (L) & $900 \mathrm{~m}$ \\
\hline Dam height (H) & $60 \mathrm{~m}$ \\
\hline Water height(h) & $0.8 \mathrm{H}$ \\
\hline Us\& Ds side slope (z:1) & $2: 1$ \\
\hline Hydraulic conductivity (outer soil), $\mathrm{k}(\mathrm{m} / \mathrm{sec})$ & $2 \times 10-4$ \\
\hline Hydraulic conductivity (core), $\mathrm{k}_{\text {core }}(\mathrm{m} / \mathrm{sec})$ & $2 \times 10^{-8}$ \\
\hline
\end{tabular}
\end{tabular}

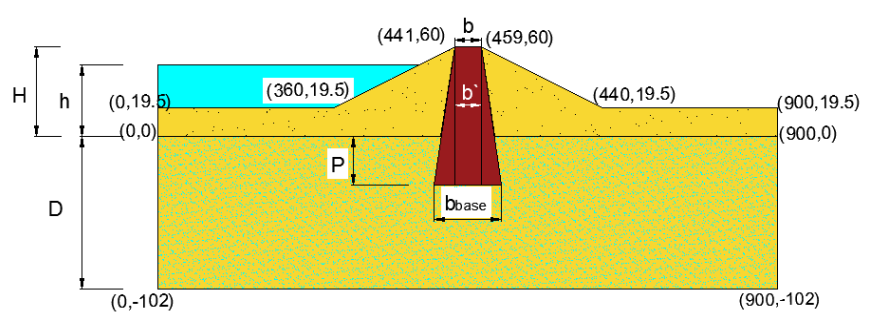

Fig. 13.Earth Dam Cross Section.

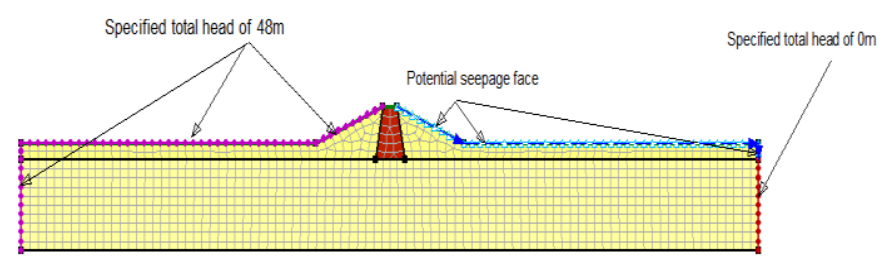

Fig. 14.Steady-state Boundary conditions.

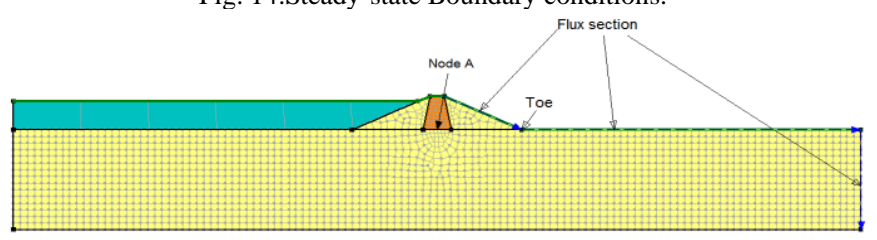

Fig. 15.Places where data are gathered.

\section{2) Results and discussion}

a) Effect of changing core permeability

To study the effect of changing relative core permeability as a ratio of dam shell permeability $\mathrm{k}_{\text {core }} / \mathrm{k}$ ) ranging from (1 to 0.001 ) on the quantity of seepage, exit gradient at toe of the dam, and pressure head at point A which is located at the center of the core base see Fig. 15.

Fig. 16 shows that the quantity of seepage decreased by about $(3.69 \%)$ by decreasing the relative core permeability $\left(\mathrm{k}_{\text {core }} / \mathrm{k}\right)$ from (1 to 0.1$),(2.2 \%)$ by decreasing the relative core permeability $\left(\mathrm{k}_{\text {core }} / \mathrm{k}\right)$ from $(0.08$ to 0.01$),(0.406 \%)$ by decreasing the relative core permeability $\left(\mathrm{k}_{\text {core }} / \mathrm{k}\right)$ from $(0.008$ to 0.001 ) and remains constant for the other values.

Fig. 17 shows that the exit gradient decreased by about $(0.26 \%)$ by decreasing the relative core permeability $\left(\mathrm{k}_{\text {core }} / \mathrm{k}\right)$ from (1 to 0.1$),(0.22 \%)$ by decreasing the relative core permeability $\left(\mathrm{k}_{\text {core }} / \mathrm{k}\right)$ from $(0.08$ to 0.01$),(0.2 \%)$ by decreasing the relative core permeability $\left(\mathrm{k}_{\text {core }} / \mathrm{k}\right)$ from $(0.008$ to 0.001 ) and remains constant for the other values.

Fig. 18 shows that the pressure head decreased by about $(1.64 \%)$ by decreasing the relative core permeability $\left(\mathrm{k}_{\mathrm{cor}} / \mathrm{k}\right)$ from (1 to 0.1$),(0.46)$ by decreasing the relative core permeability $\left(\mathrm{k}_{\text {core }} / \mathrm{k}\right)$ from $(0.08$ to 0.1$),(0.028 \%)$ by decreasing the relative core permeability $\left(\mathrm{k}_{\text {core }} / \mathrm{k}\right)$ from (0.008 to 0.001$)$ and remains constant for the other values. 


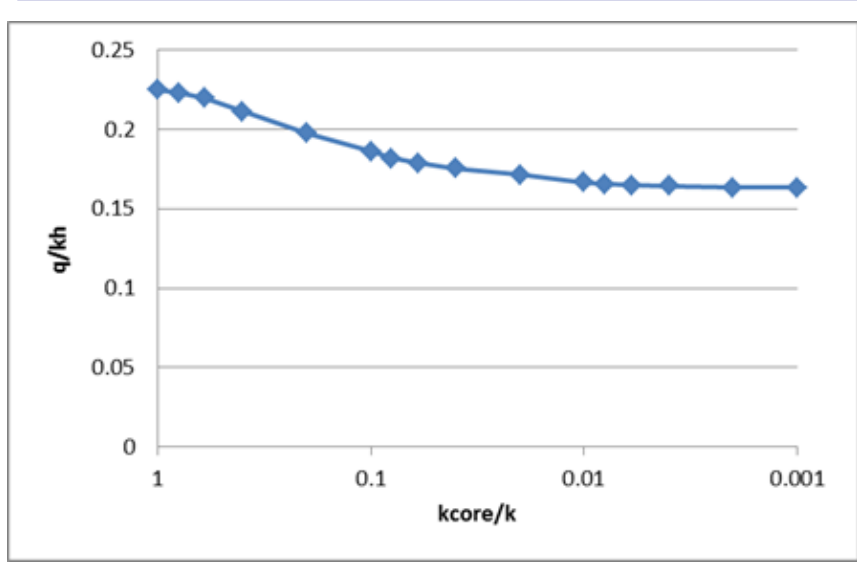

Fig. 16. Effect of different values of core permeability on the quantity of seepage.

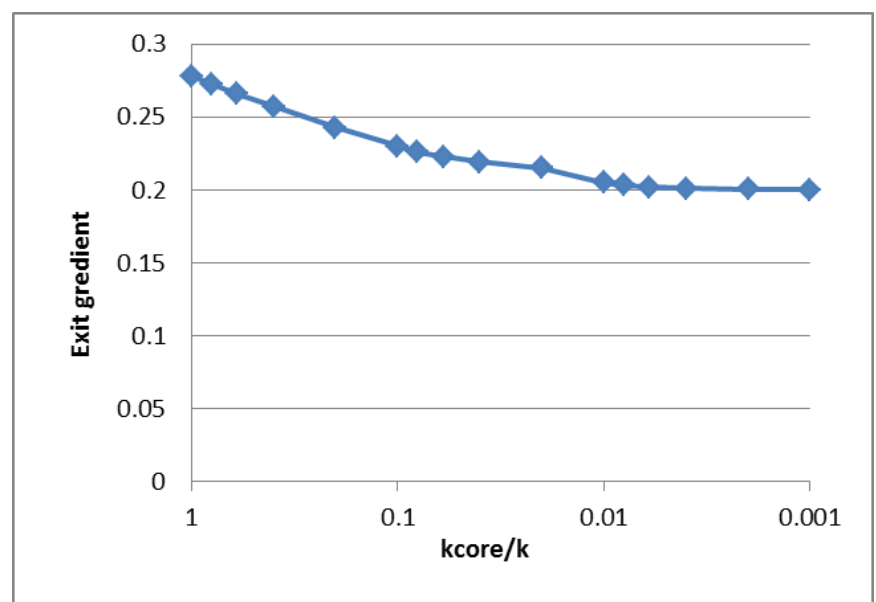

Fig. 17. Effect of different values of core permeability on exit gradient.

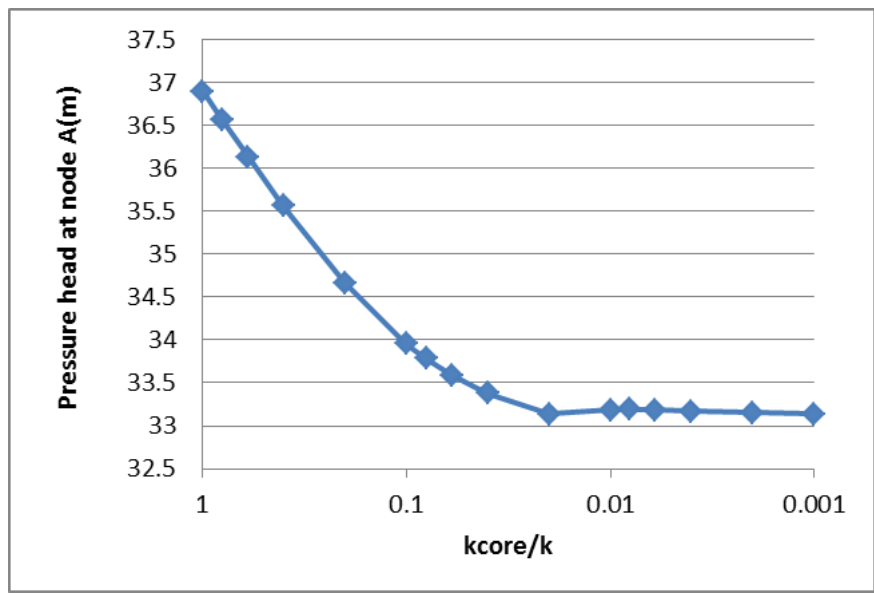

Fig. 18. Effect of different values of core permeability on pressure head at node (A) which is located at the center of the core base.

b) Effect of total core thickness

Fig. 19 shows that the quantity of seepage decreased by about $(1 \%)$ by increasing the relative core thickness $(\mathrm{b} / \mathrm{b})$ from ( 0.1 to 0.6$)$, and $(2 \%)$ by increasing the relative core thickness from (0.7 to 1$)$.

c) Effect of core base thickness

Fig. 20 shows the effect of changing relative core base thickness $\left(b_{\text {base }} / \mathrm{b}\right)$ from (1 to 5$)$. The quantity of seepage was decreased by about $(7.7 \%)$.

\section{d) Effect of core penetration depth}

Fig. 21 shows that by increasing the relative core penetration depth from ( 0 to 0.5$)$, the quantity of seepage decreased by about $(24.1 \%)$, and $(77.4 \%)$ when the relative core penetration depth ranging from (0.5 to 1$)$.

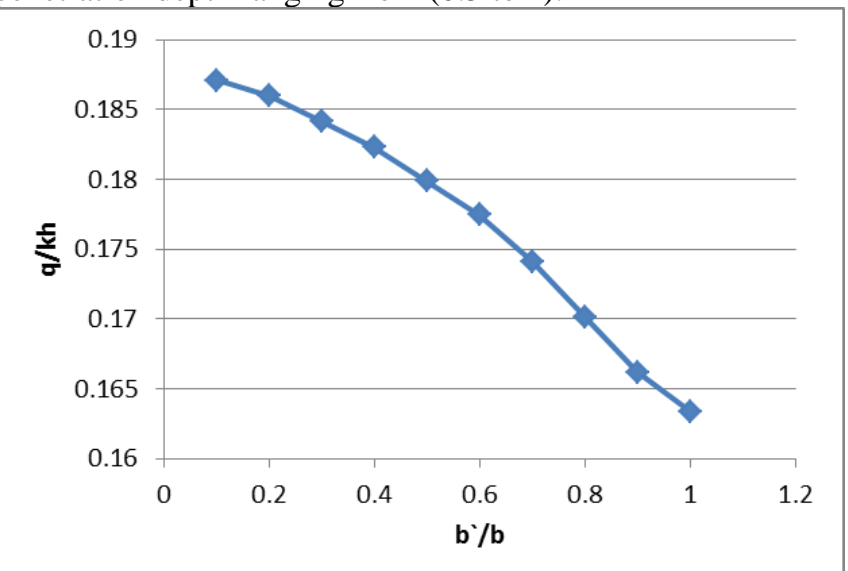

Fig. 19. Effect of different values of core thickness on the quantity of seepage at $K_{\text {core }} / \mathrm{k}=0.001$.

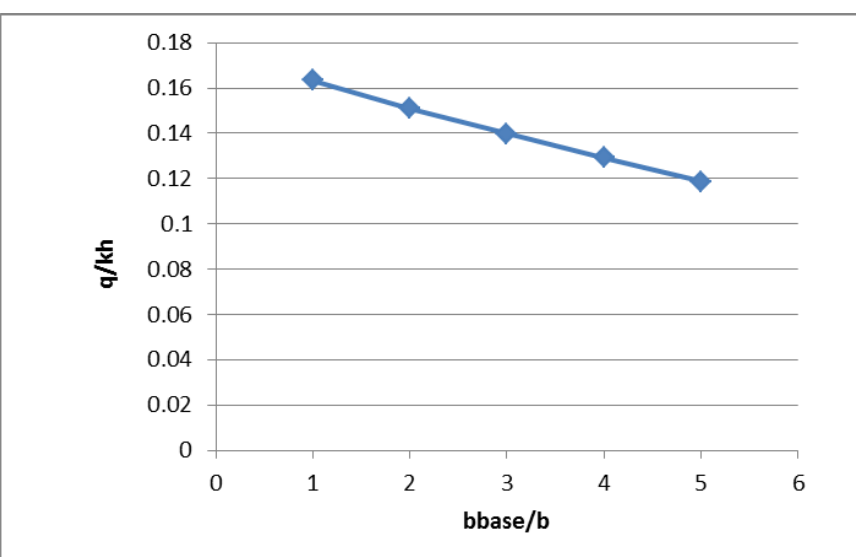

Fig. 20 Effect of different values of core base thickness on the quantity of seepage at $\mathrm{K}_{\text {core }} / \mathrm{k}=0.001$.

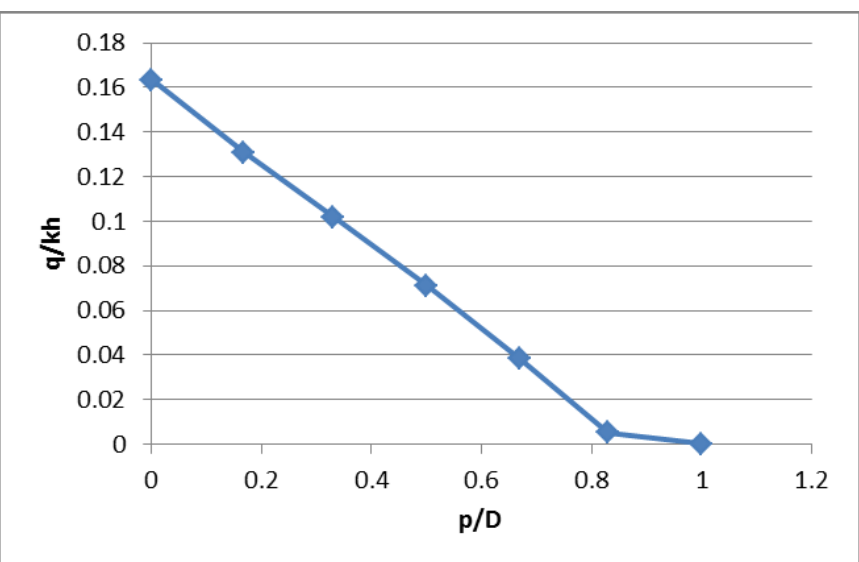

Fig. 21. Effect of different values of core penetration depth on seepage rate at $\mathrm{K}_{\text {core }} / \mathrm{k}=0.001$.

\section{B. Slope/w analysis}

SLOPE/W is one of the most common and popular software applications which used for the stability analysis of a slope. This is a part of Geostudio software application. This 
application was created based on limit equilibrium method and includes several types of analysis like Fellenius, Bishop, Janbu, spencer and Morgenstern -Price methods.

The GLE formulation is based on two factors of safety equations; one equation gives the factor of safety with respect to moment equilibrium $\left(\mathrm{F}_{\mathrm{m}}\right)$ while the other equation gives the factor of safety with respect to horizontal force equilibrium $\left(F_{f}\right)$ as shown in equation $(3,4)[31]$.

$$
\begin{gathered}
F_{f}=\frac{\sum\left(c^{`} \beta \cos \alpha+(N-u \beta) \cos \alpha \tan \emptyset^{\prime}\right)}{\sum W X-\sum N \sin \alpha+\sum k_{w} \pm \sum D \cos \omega \pm \sum A} \\
F_{m}=\frac{\sum\left(c^{\prime} \beta R+(N-u \beta) R \tan \emptyset^{\prime}\right)}{\sum W X-\sum N f+\sum K W_{e} \pm \sum D d \pm \sum A a}
\end{gathered}
$$

Fig. 22 shows the effect of the relative core permeability ratio (k core/k) from (1 to 0.001$)$ on the stability of upstream and downstream faces of earth dam. It is found that by decreasing core permeability, the upstream factor of safety decreased and the downstream factor of safety increased.

Fig. 23 shows the effect of change of the relative core thickness ( $\left.\mathrm{b}^{`} / \mathrm{b}\right)$ from $(0.1$ to 1$)$. It is found that

The core thickness is inversely proportional to upstream factor of safety, and gives no effect of downstream factor of safety.

Fig. 24 shows the effect the relative core base thickness $\left(b_{\text {base }} / \mathrm{b}\right.$ ) from (1 to 5$)$. It is found that

The core base thickness is inversely proportional to upstream and downstream faces factor of safety (if no penetration because of the fast flow rate through foundation).

Fig. 25 shows the effect of the relative core penetration depth (p/D) from (0 to 1$)$. It is found that

The core penetration depth is inversely proportional to upstream face factor of safety, and is directly proportional to downstream face factor of safety.

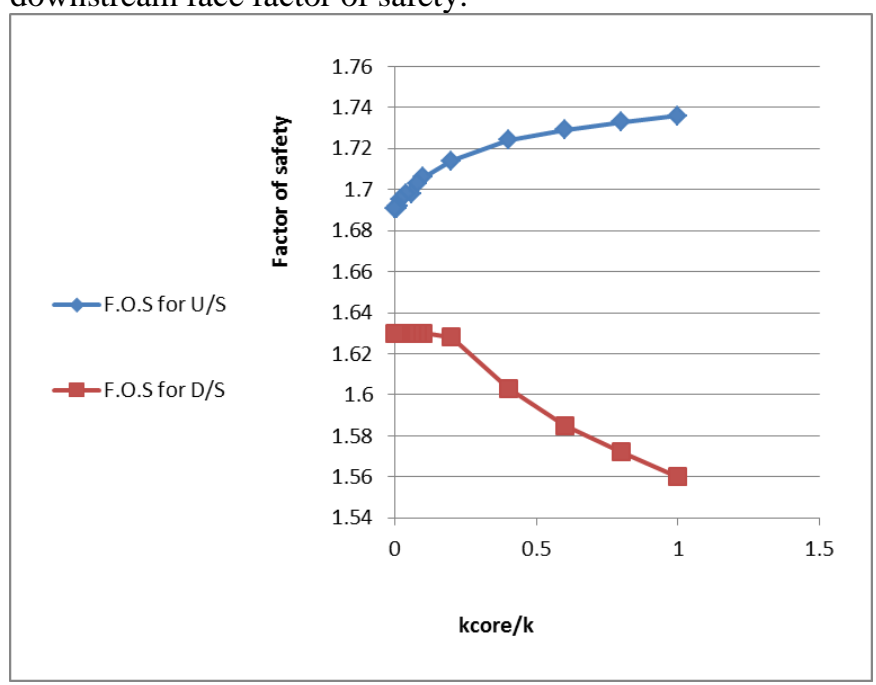

Fig. 22: Effect of changing values of core thickness on stability of upstream and downstream slopes of earth dam at $\mathrm{K}_{\text {core }} / \mathrm{k}=0.001$.

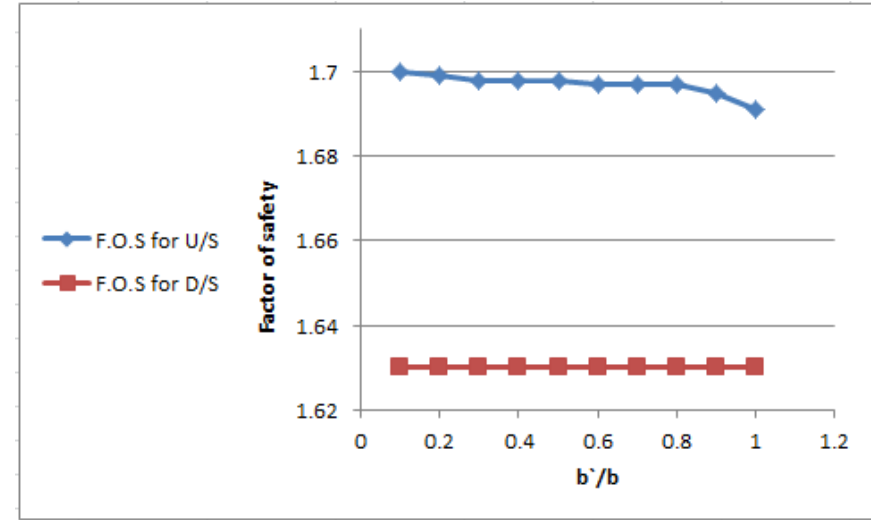

Fig. 23: Effect of changing values of core thickness on stability of upstream and downstream slopes of earth dam at Kcore/k=0.001.

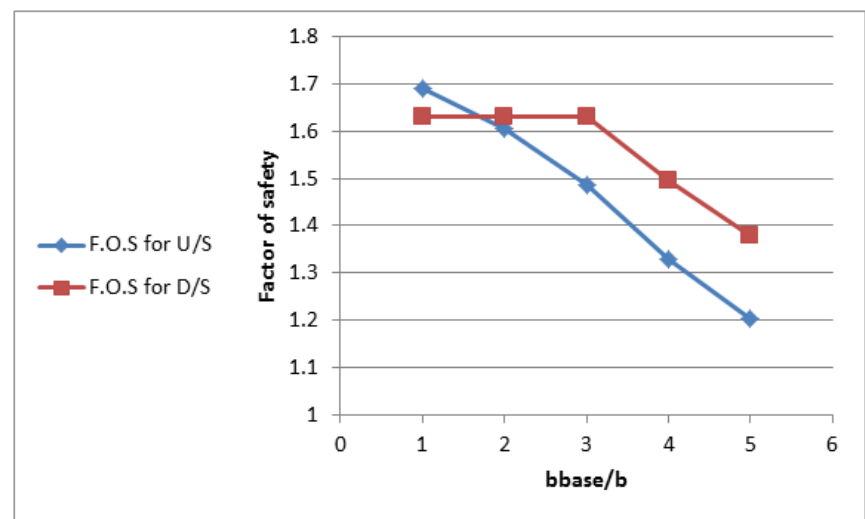

Fig. 24: Effect of changing values of core base thickness on stability of upstream and downstream slopes of earth dam at Kcore $/ \mathrm{k}=0.001$.

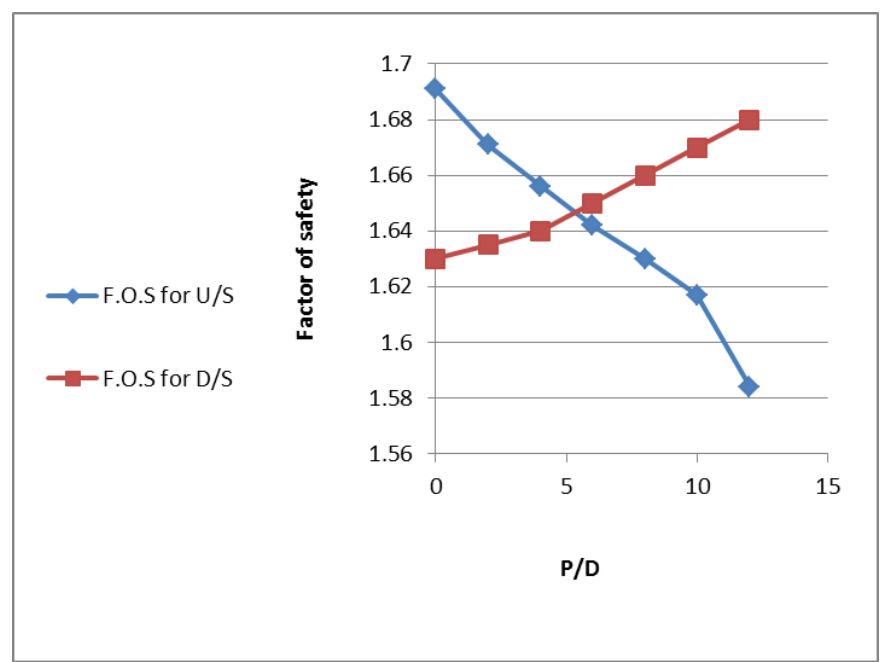

Fig. 25: Effect of changing values of core penetration depth on stability of upstream and downstream slopes of earth dam at Kcore/k=0.001.

\section{CONCLUSION}

In the present work, experimental and numerical analysis have been performed on earth dam to study the seepage e flow through earth embankment and how to reduce it by using an internal core. The numerical analysis was verified using experimental model, it is noticed that the max difference is $18 \%$.

The effect of core permeability, total core thickness, base core thickness and core penetration has been studied numerically using the GEOSTUDIO software. SEEP/W was 
used to compute seepage, while SLOPE/W was used for the analysis of slope stability, the results of this study showed that:

1) Decreasing relative core permeability $\mathrm{k}_{\text {core }} / \mathrm{k}$ from 1 to 0.001 , gives a reduction of about $27.5 \%$ in the relative seepage quantity (q/kh), 28\% in exit gradient and about $10 \%$ in pressure head.

2) Increasing relative total core thickness (b`/b) from 0.1 to 1 , gives a reduction of about $12.7 \%$ in the relative seepage quantity $(\mathrm{q} / \mathrm{kh})$

3) Increasing of base core thickness (b base/b) from core 1 to 5 , gives a reduction of about $27.3 \%$ in the relative seepage quantity $(\mathrm{q} / \mathrm{kh})$.

4) Increasing the relative penetration depth (p/D) from core 0 to 1 , gives a reduction of about $99.98 \%$ in the relative seepage quantity (q/kh).

5) Increasing of side slopes $(\mathrm{H}: \mathrm{V})$, gives a noticeable drop of seepage line is observed with increasing of downstream slope stability.

6) SLOPE/W program is used for analyzing the stability of earth dam slopes using Morgenstern-price method; it's concluded that:

7) Decreasing relative core permeability $\mathrm{k}_{\text {core }} / \mathrm{k}$ from 1 to 0.001 , gives an increase of downstream factor of safety with critical factor of safety 1.63 .

8) Increasing relative total core thickness ( $b / b)$ from 0.1 to 1 , gives no effect of downstream factor of safety with a constant critical factor of safety 1.63 .

9) Increasing of base core thickness $\left(b_{\text {base }} / b\right)$ from core 1 to 5, gives a reduction of downstream factor of safety (if no core penetration depth through foundation because of the fast flow rate through foundation) with critical factor of safety 1.378

10) Increasing the relative penetration depth (P/D) from core 0 to 1 , gives an increase of downstream factor of safety with critical factor of safety 1.68

\section{REFERENCES}

[1] L. M. Zhang, Y. Xu and J.S. Jia" Analysis of earth dam failures", A database approach. Georisk, Vol.3, No.3, PP. 184-189, 2009.

[2] A. Javdani, M. Yusefzadeh-Fard and G. Moradi, "A study on the effect of implementing waterproof membrane on reduction of water seepage from earthen dams (case study: Shahid madani earthen dam, Tabriz, Iran)", Cumhuriyet Üniversitesi Fen-Edebiyat Fakültesi Fen Bilimleri Dergisi Vol.36, No3, PP.2693-2717, 2015

[3] R. Flores-Berrones and N. P. Lopez-Acosta, "Internal erosion due to water flow through earth dams and earth structures", INTECH Open Access Publisher, PP.283-306, 2011

[4] R. P. Sharma and A. Kumar, "Case histories of earthen dam failures", International Conference on Case Histories in Geotechnical Engineering, Vol.3, PP. 1-7, 2013.

[5] H. R. Cedergren," Seepage, drainage, and flow nets", John Wiley \& Sons, Vol. 16, 1997.

[6] R. Awal, H. Nakagawa, K. Kawaike, Y. Baba and H. Zhang, "Three dimensional transient seepage and slope stability analysis of landslide dam", Annuals of Disaster Prevention Research Institute, Kyoto University, No. 52B, PP. 689-696, 2009.

[7] C. I. Sachpazis, "Experimental conceptualisation of the flow net system construction inside the body of homogeneous earth embankment dams", J of the Electronic Journal of Geotechnical Engineering (E.J.G.E.), Vol. 19, PP. 2113-2136, 2014

[8] A. Djehiche, R. Amieur and M. Gafsi, M, "The seepage through the earth dams with a vertical drain: an experimental study", Journal of Environmental Research and Development, Vol.8, No.3 PP 471, 2014
[9] M. H. Mowafy, M. N. Salem, E. A. El-Nikhily and Y. E. Shaaban, "A study of unsteady flow through earth dams", The Egyptian International Journal of Engineering Sciences \& Technology, Vol.17, No1, PP. 1686-1696, 2014.

[10] H. J. Kanchana and H. S. Prasanna, "Adequacy of seepage analysis in core section of the earthen dam with different mix proportions", Aquatic Procedia, Vol. 4, PP. 868-875, 2015

[11] A. Vazquez Borragan, "Modelling internal erosion within an embankment dam prior to breaching", M. Sc., KTH Royal Institute of Technology, 2015.

[12] X. Luofeng, and D. Xiangbao, "Study on physical model experiment of dam's seepage stability base on coastal sand", Procedia Engineering, Vol.28, PP.534-541, 2012.

[13] A. Malekpour, D. F. Zade, A. H. Z. Dalir and J. Sadrekarimi, "Effect of horizontal drain size on the stability of an embankment dam in steady and transient seepage conditions", Turkish Journal of Engineering and Environmental Sciences, Vol.36, No.2, PP. 139-152, 2012.

[14] Y. Q. Xu, K. Unami, K and T. Kawachi, "Optimal hydraulic design of earth dam cross section using saturated-unsaturated seepage flow model", Advances in Water Resources, Vol.26, No.1, PP. 1-7, 2003.

[15] G. Tayfur, D. Swiatek, A. Wita and V. P. Singh, " Case study: Finite element method and artificial neural network models for flow through Jeziorsko earthfill dam in Poland", Journal of Hydraulic Engineering, Vol.131, No.6, PP. 431-440, 2005.

[16] Q. Chen, Q and L. M. Zhang, "Three-dimensional analysis of water infiltration into the Gouhou rock fill dam using saturated unsaturated seepage theory", Canadian Geotechnical Journal,Vol.43, No.5, PP. $449-461,2006$

[17] J. F. Fu and J.I.N. Sheng, "A study on unsteady seepage flow through dam", Journal of Hydrodynamics, Ser. B, Vol.21, No.4, PP. 499-504, 2009

[18] A. N. Giglou and A. Zeraatparvar, "Seepage estimation through earth dams", Journal of Basic and Applied Scientific Research, Vol.2, No.8, PP. 7861-7865, 2012

[19] Q. LI and J. LIU, "Numerical analysis of the seepage field in coredam". School of civil engineering and architecture", Southwes Petroleum University, Chengdu, China, 610500, PP. 492-499, 2010.

[20] K. S. Ismaeel and B. M. Noori, "Evaluation of seepage and stability of Duhok dam", AL Rafdain Engineering Journal, Vol.19, No.1, PP.42-58, 2011 .

[21] R. R. Shakir, "Effect of an impervious core constructed into a large earth dam on the quantity of seepage", Thi-Qar University Journal for Engineering Sciences, Vol.2, No.2, PP. 1-17, 2011

[22] H. Hasani, J. Mamizadeh and H. Karimi, "Stability of slope and seepage analysis in earth fills dams using numerical models (case study: Ilam dam-Iran)", World Applied Sciences Journal, Vol.21, No.9, PP.1398-1402, 2013

[23] A. Fakhari and A. Ghanbari, "A simple method for calculating the seepage from earth dams with clay core", Journal of GeoEngineering, Vol.8, No. 1, PP. 27-32, 2013

[24] F. Karampoor and R. Riazi, "Investigation the effect of clay core in seepage from non-homogenous earth dams using SEEP/W Model", Journal of scientific research and development, Vol.2, No.5, PP. 280$285,2015$.

[25] A. A. J. Jamel, "Analysis and estimation of seepage through homogenous earth dam without filter", Diyala Journal of Engineering Sciences, Vol.9, No.2, PP. 38-49, 2016.

[26] S. I. Khassaf and A. M. Madhloom, "Effect of impervious core on seepage through zoned earth dam (case study: Khassa Chai dam)", International Journal of Scientific \& Engineering Research, Vol.8, No.2, PP. 1053-1064, 2017

[27] I. Arshad, M. M. Babar and N. Javed, "Numerical analysis of seepage and slope stability in an earthen dam by using geo-slope software". PSM Biological Research, Vol.2, No.1, PP. 13-20, 2017.

[28] J. Kachare and S. Jagtap, "Seepage analysis of Gangapur, the earthen dam using geo-studio software", International Journal of Recent Advances in Engineering \& Technology, 2017

[29] T. Souliyavong, C. Gallage, P. Egodawatta and B. Maher, "Factors affecting the stability analysis of earth dam slopes subjected to reservoir drawdown In Proceedings of the Second International Conference on Geotechnique, Construction Materials and Environment", The GEOMATE International Society, pp. 507-512, 2012 . 
[30] S. H. Abdulkareem, T. M. Ahmed, and A. H. B. Ghazali, "Safety assessment of earth dams in Kurdistan region, Iraq based on seepage simulation and surveillance data", Bund. O, Vol. 19, PP.3597-3613, 2014.

[31] E. Spencer1967, "A method of analysis of embankments assuming parallel inter-slice forces", Geotechnique, Vol.17, No.1, pp. 11-26, 1967.

\section{LIST OF SYMBOLS AND VARIABLE}

H: The Total Head,

$\mathbf{k}_{\mathbf{x}}$ : The hydraulic conductivity in $\mathrm{x}$ direction,

$\mathbf{k}_{\mathbf{y}}$ : The hydraulic conductivity in y direction,

Q: the applied boundary flux,

$\frac{\mathrm{\partial}}{\mathrm{\partial x}}$ : Rate of change of gradient in $\mathrm{x}$ direction,

$\frac{\partial}{\partial y}$ : Rate of change of gradient in y direction,

$\frac{\partial \theta}{\partial t}$ : Rate of change in volumetric water content or water

stored in the soil, required for transient analysis,

W: the total weight of a slice of width $b$ and height $h$,

$\mathbf{N}$ : the total normal force on the base of the slice,

$\mathbf{X}$ : the vertical interslice shear forces. Subscripts $\mathrm{L}$ and $\mathrm{R}$ define the left and right sides of the slice respectively,

D: an external point load,

$\mathbf{k}_{\mathbf{w}}$ : The horizontal seismic load applied through the centroid of each slice,
R: the radius for a circular slip surface or the moment arm associated with the mobilized shear force, $\mathrm{s}_{\mathrm{m}}$ for any shape of slip surface,

f: the perpendicular offset of the normal force from the centre of rotation or from the centre of moments. It is assumed that $\mathrm{f}$ distances on the right side of the centre of rotation of a negative slope (i.e., a right-facing slope) are negative and those on the left side of the centre of rotation are positive. For positive slopes, the sign convention is reversed,

$\mathbf{x}$ : the horizontal distance from the centreline of each slice to the centre of rotation or to the centre of moments,

e: the vertical distance from the centroid of each slice to the centre of rotation or to the centre of moments,

d: the perpendicular distance from a point load to the centre of rotation or to the centre of moments,

h: the vertical distance from the centre of the base of each slice to the uppermost line in the geometry (i.e., generally ground surface),

a: the perpendicular distance from the resultant external water force to the centre of rotation or to the centre of moments. The $\mathrm{L}$ and $\mathrm{R}$ subscripts designate the left and right sides of the slope, respectively,

A: the resultant external water forces. The $\mathrm{L}$ and $\mathrm{R}$ subscripts designate the left and right sides of the slope, respectively, $\omega$ :the angle of the point load from the horizontal. This angle is measured counter-clockwise from the positive $\mathrm{x}$-axis,

$\alpha$ : the angle between the tangent to the centre of the base of each slice and the horizontal. 